\title{
CAPITAL SOCIAL Y EDUCACIÓN DE CALIDAD. EL PROGRAMA DE NIÑAS Y NIÑOS TALENTO DE LA CIUDAD DE MÉXICO
}

SOCIAL CAPITAL AND QUALITY EDUCATION. The PROGRAM OF GIRLS AND BOYS TALENT OF THE MEXICO CITY

Mario M. Carrillo Huerta*

(Recibido: junio, 2016/Aceptado: octubre, 2016)

\section{Resumen}

Impulsar el talento es muy importante en educación básica porque en esa etapa los niños están en formación y necesitan ser estimulados para desarrollar al máximo sus capacidades y con ello aumentar el potencial de sus ingresos futuros individuales y familiares, así como el capital social de la comunidad. No obstante, los sistemas educativos, por lo regular, no atienden las diferencias en habilidades y ritmos de aprendizaje de los educandos. En 2007, el gobierno de la Ciudad de México implantó el Programa de Niñas y Niños Talento, que ofrece cursos extraescolares especializados en disciplinas de las áreas de las ciencias, las artes y el deporte, a estudiantes talentosos en escuelas públicas de educación básica de la ciudad. Este trabajo presenta los resultados de un análisis del impacto de dicho programa en el comportamiento socioafectivo y en las habilidades creativas de los educandos, realizado con la ayuda de un análisis econométrico, a partir de información proveniente de dos encuestas levantadas entre beneficiarios del programa en 2008 y 2010. Se concluye que el programa los ha impactado positivamente en ambos tipos de comportamiento, lo que sugiere un

\footnotetext{
* Profesor-investigador del Instituto de Ciencias de Gobierno y Desarrollo Estratégico de la Benemérita Universidad Autónoma de Puebla. <mmch@prodigy.net.mx>.
} 
impacto positivo en su asociatividad, que es el elemento central del capital social de la comunidad.

Palabras clave: capital social, niños talentosos, educación. Clasificación JEL: I21, I38.

\begin{abstract}
As talented children in early stages of education are in a formative process, they must be stimulated to develop at their maximum capacity in order to increase their potential future incomes (for them and for their families) as well as their communities social capital. However, in less developed areas educational systems usually do not attend the students differences in talent and learning capabilities. In 2007, the government of Mexico City launched a program called Niñas y Niños Talento, with the purpose of offering additional specialized courses in disciplines from the areas of sciences, arts and sports to talented children enrolled in the city's public schools of basic education (primary and lower secondary). This paper presents the results of an analysis of the impact of that program on the students' socio-affective and creative behavior and capabilities, carried out with the help of econometric analysis, applied to data gathered from two surveys directed by the author among beneficiaries of the program in 2008 and 2010. It is concluded that the program has important positive effects on both types of students behavior which suggests a positive effect on the population's associative behavior, which is the defining element of social capital.
\end{abstract}

Key words: social capital, talented children, education.

JEL classification: I21, I.

\title{
1. Introducción
}

En general, los sistemas educativos no crean entornos que respondan a las necesidades de todos los educandos, al no tomar en cuenta sus diferencias en habilidades y ritmos de aprendizaje. En educación básica esto tiene como consecuencia que muchas niñas y muchos niños no desarrollen plenamente sus capacidades, y como resultado experimenten dificultades de aprendizaje 
y de participación en una escuela donde las exigencias son las mismas para todos y no se consideran sus múltiples talentos. ${ }^{1}$

El impulso al talento de niñas y niños desde edades tempranas es de suma importancia en educación básica (primaria y secundaria) ya que en esa etapa están en formación y necesitan ser estimulados para desarrollar al máximo sus capacidades y así incrementar el potencial tanto de sus ingresos futuros y los de sus familias, como del capital social de la comunidad. Sin embargo, y por diversas razones (incluida la falta de recursos) en la mayoría de las áreas en desarrollo los servicios educativos siguen siendo uniformes para todas las niñas y todos los niños y no se ofrecen procesos de educación especial para estimular los talentos especiales de los educandos.

En ese marco de referencia, el gobierno de la Ciudad de México inició el 29 de agosto de 2007 el Programa de Niñas y Niños Talento, cuyo objetivo central era... garantizar la equidad, el bienestar y la justicia social a las niñas y los niños sobresalientes y con talento de la Ciudad de México (Ebrard, Prats y Carrillo, 2009: 2). Este programa continúa vigente hasta esta fecha, y consiste básicamente en apoyar a niñas, niños y jóvenes que estudien educación primaria o secundaria en escuelas públicas de la entidad con promedios de calificaciones entre 9.0 y 10.0 (en una escala de cero a diez), ofreciéndoles clases extraescolares, equivalentes a una hora semanal en las disciplinas de su talento revelado en los campos de las artes, los deportes y los conocimientos científicos, y otorgándoles también un estímulo económico equivalente a 3000.00 mexicanos anuales, con el objeto de que puedan adquirir algunos materiales adicionales, necesarios para su adecuado desempeño académico. ${ }^{2}$

\footnotetext{
${ }^{1}$ En la mayoría de los casos, las actitudes de los docentes, la falta de formación para atender la diversidad, la homogeneidad de la enseñanza, la escasez de recursos, la rigidez de los planes de estudio y de los criterios de evaluación, son factores que no han permitido crear entornos educativos que respondan a las necesidades de todos los educandos, tomando en consideración las diferencias de sus habilidades y ritmos de aprendizaje. Ante esta situación, un grupo comúnmente ignorado es el de las alumnas y alumnos con capacidades sobresalientes, ya que se supone erróneamente que "les irá bien" sin necesidad de proporcionarles mayores recursos en su enseñanza. Sin embargo, ellas y ellos requieren entornos que optimicen su desarrollo y aprendizaje, y maestros que conozcan sus características y necesidades educativas y que sean capaces de responder a ellas. Si desde la enseñanza primaria o antes, los niños se ven involucrados en una atmósfera de desarrollo del talento, se favorecerá la formación de cualidades de la personalidad y de los valores individuales y sociales relacionados con la excelencia.

2 El estímulo se entrega de la siguiente forma: 150.00 pesos mensuales a través de una tarjeta bancaria y, por medio de una cuenta de ahorro se van acumulando 100.00 pesos cada mes, los cuales se hacen efectivos al final de cada semestre. Además, el programa contempla que a las niñas y a los niños se les proporcionen los servicios y materiales necesarios para sus clases extraescolares. En el primer año de su operación, el programa atendió a un poco más de 100000 estudiantes talentosos de la Ciudad de México, lo que representó una inversión de 300 millones de pesos.
} 


\section{Objetivo general}

El objetivo principal de este trabajo es presentar los resultados de un análisis del impacto de dicho programa en dos variables relacionadas con el capital social: la socioafectividad y la creatividad de los educandos. El ejercicio se realizó a partir de información proveniente de encuestas levantadas entre beneficiarios del programa y entre sus familiares en 2008 y 2010, y se procesó con la ayuda de la aplicación de un modelo econométrico diseñado para el efecto.

En las secciones subsecuentes, el trabajo presenta algunas anotaciones de aspectos teóricos tanto en el tema del talento como en el del capital social. Luego se presenta una descripción general del programa de Niñas y Niños Talento, seguida de la presentación del análisis de sus impactos en el comportamiento socioafectivo y en las habilidades creativas de los estudiantes así como de los resultados del análisis econométrico. En la última parte del trabajo, se ofrece un resumen y algunas consideraciones finales.

\section{El marco teórico del estudio de niñas y niños talentosos}

\subsection{Educación y diversidad}

La diversidad es la pluralidad de intereses, ideas y comportamientos que se manifiestan en el ámbito educativo, y tiene su origen en causas procedentes de factores sociales, económicos, culturales, geográficos, étnicos y religiosos (Alegre, 2000; Álvarez y Bisquerra, 1996). Los factores a través de los que se manifiesta la diversidad son agrupados en tres bloques: 1) individuales, 2) de grupo y 3) de contexto.

Las diferencias individuales se pueden dar por: a) su etapa de desarrollo, $b$ ) conocimientos previos, $c$ ) motivación especial, $d$ ) interés personal, $e$ ) expectativas, $f$ ) estilos de aprendizaje y/o $g$ ) procesos cognitivos. Las diferencias de grupo pueden ser: $a$ ) étnicas; $b$ ) de género, o; $c$ ) socioculturales. Los elementos del contexto incluyen: $a$ ) escolar, $b$ ) familiar, y/o c) social. (Álvarez y Bisquerra, 1996).

Todo parece indicar que estas diferencias no han sido tomadas en cuenta de manera continua por los sistemas educativos dominantes. Aun reconociendo la existencia de la diversidad, los sistemas educativos se caracterizan por ofrecer respuestas educativas uniformes. Según la UNESCO 
(2004) esta situación explica en gran medida los altos índices de reprobación, deserción y de bajos niveles de aprendizaje en los países de América Latina. Las niñas y los niños talentosos son una manifestación de esta diversidad, por lo que requieren una respuesta educativa que tome en cuenta sus necesidades de desarrollo.

\subsection{Aproximaciones al significado del término talento}

Según Alonso y Benito (1996) la atención adecuada a niñas y niños talentosos en ocasiones se dificulta debido a que existen términos que se utilizan como sinónimos del talento, tales como superdotación, alta habilidad, precocidad, prodigio o genio y proponen hacer una distinción entre todos ellos para llegar a una aproximación más cercana al término talento. ${ }^{3}$

Afirman que 'talento' se refiere a la capacidad de un rendimiento superior en alguna de las áreas del conocimiento o de la conducta humana, tales como lenguas, ciencias sociales, ciencias naturales y matemáticas, o campos artísticos como música, artes gráficas y plásticas, artes representativas y mecánicas, así como el ámbito de las relaciones humanas.

En estas definiciones se hace referencia a aspectos que se destacan en la persona; cuando son más de uno, la literatura especializada ha convenido en llamarle superdotación y no talento. Por lo tanto el concepto de talento alude a aquellos alumnos que tienen capacidades excepcionales en un ámbito específico, mientras que la superdotación incluye varios ámbitos o áreas. ${ }^{4}$

\footnotetext{
${ }^{3}$ En ocasiones, a las niñas y los niños sobresalientes se les identifica con otros conceptos. Por ejemplo, la concepción de precocidad se refiere al desarrollo temprano de una determinada área. El niño prodigio se define como aquel que realiza una actividad fuera de lo común para su edad; realizan un producto que llama la atención en un campo específico que hace competencia con los niveles de rendimiento del adulto. El niño genio se define como la persona que, dentro de la superdotación y su compromiso con la tarea, logra una obra genial. El genio científico depende de cierto tipo de capacidades, rasgos de temperamento, personalidad, motivación, pero su concepto se define estrictamente en términos de los efectos de los productos creativos propios de la comunidad científica (Alonso y Benito, 1996).

${ }^{4}$ Gagné (1993) menciona que la emergencia de un talento particular resulta de la aplicación de una o más aptitudes al dominio, maestría y destrezas del conocimiento, mediado por el apoyo de variables o catalizadores intrapersonales (por ejemplo, la motivación, la confianza en sí mismo) y ambientales (como la familia, la escuela, la comunidad, etc.), así como el aprendizaje sistemático y la práctica continua. Por ello, el talento tiene un carácter evolutivo, de modo que no solamente el talento actual es relevante, sino que el talento potencial es igualmente importante, y es éste último sobre el que se puede hacer una buena intervención educativa al nivel curricular y de estrategias de enseñanza, en el marco.
} 


\subsection{Elementos teóricos del concepto talento}

En la literatura de las niñas y los niños talentosos existe una gran diversidad de autores con definiciones y teorías que expresan sus diferentes posturas. Recientemente se han podido diferenciar cinco grandes enfoques teóricos acerca del concepto de talento, que ofrecen definiciones orientadas: 1) a lo innato o genético, 2) al logro alcanzado, 3) a la interacción entre lo innato y el medio ambiente, 4) a modelos cognitivos y/o 5) a modelos sistémicos. A continuación se presenta un resumen de esos enfoques.

\subsection{Definiciones orientadas al talento innato o genético}

Terman (1925) propone el concepto de talento innato o genético, que destaca por su determinismo biológico y la popularización del cociente intelectual (CI). Este autor considera que la inteligencia revelada, mediante un test (prueba), está genéticamente determinada, debido a que la inteligencia es una habilidad unitaria heredada y una alta inteligencia no asegura un alto rendimiento.

En el informe de Marland (1972) se establece la definición oficial del talento asumida en los Estados Unidos de Norteamérica por encargo del Congreso, la cual manifiesta que los niños dotados y talentosos son aquellos que son capaces de un alto rendimiento. Incluyen a los niños que han demostrado sus logros y/o habilidades potenciales (aisladas o combinadas) en cualesquiera de las seis áreas, a saber:

1. Habilidad intelectual general: presentan una elevada capacidad de aprendizaje.

2. Habilidad sicomotora: destrezas de tipo motriz, relacionadas tanto con el mundo del arte como del deporte.

3. Habilidad de las artes visuales o representativas: destrezas relacionadas con la percepción o la representación artística (pintura, fotografía, teatro).

4. Habilidad en el liderazgo: capacidades intelectuales y rasgos peculiares de la personalidad, que le permiten interactuar de forma especial con su grupo.

5. Aptitud académica específica: rendimiento académico superior en cualquiera de las áreas del curriculum (matemáticas, física, lengua).

6. Pensamiento creativo: presentan elevadas aptitudes creativas. 
Con la utilización de los criterios anteriores de identificación de los niños dotados y talentosos se clasifica una población escolar mínima entre 3 y 5\% (Passow, 1993).

\subsection{Modelos orientados al logro académico alcazando}

Los autores de estos modelos proponen la existencia de un determinado nivel de capacidad o talento como condición necesaria para el alto rendimiento, el cual es un resultado observable y medible (Mönks y Mason, 2000).

Dentro de este enfoque, la teoría más conocida es la de los tres anillos de Renzulli (1986), quien concibe que el talento implica el factor cognitivo y una interacción entre tres grupos básicos de rasgos humanos, consistentes en: 1. Capacidades por encima de la media, 2. Fuertes niveles de compromiso con la tarea y 3. Fuertes dotes de creatividad. Así, las niñas y los niños talentosos son los que poseen (o son capaces de desarrollar) este conjunto compuesto de características y los aplican en cualquier área potencialmente válida de actuación humana (Renzulli, 1986).

Quienes manifiestan o son capaces de desarrollar una interacción entre estos tres anillos requieren de una gran variedad de oportunidades y de servicios educativos, que habitualmente no proporcionan los programas regulares de enseñanza. ${ }^{5}$

\subsection{Modelos basados en la interacción entre talento y ambiente}

Mönks (2003) propone una modificación y extensión de la "teoría de los tres anillos" de Renzulli, de manera que su modelo de superdotación multidimensional considera el talento como una capacidad de factores múltiples al contener elementos de la personalidad y del medio ambiente de los niños que lo tienen.

En cuanto a los elementos de la personalidad, el alto nivel de compromiso con la tarea fue reemplazado por la motivación, la cual incluye el compromiso con la tarea, asumir riesgos, perspectiva futura, anticipación,

\footnotetext{
${ }^{5}$ La teoría de Renzulli (1986) permite identificar al menos dos formas de inteligencia superior: la académica y la creativoproductiva. El autor señala que la superdotación tiene que ser vista como una manifestación de potencial humano que puede desarrollarse en ciertas personas, en ciertos momentos y bajo ciertas circunstancias.
} 
planeación y factores emocionales; además, se considera un criterio más liberal de "habilidad por encima del promedio". ${ }^{6}$

En los elementos del medio ambiente se incluye el contexto social principal en el cual el niño y el adolescente maduran: familia, grupo de compañeros y colegio. La emergencia y el desarrollo del potencial dotado dependen en gran parte de un ambiente favorable. Los pares intelectuales o de igual desarrollo son personas significantes que son necesitadas para el desarrollo social y sicológico saludable. Todos los niños necesitan pares para interactuar, con quien y de quien aprender, y esto es cierto también con el dotado.

En resumen, Mönks (2003), desde su concepción del desarrollo de naturaleza interactiva, considera para el talento tres factores de la personalidad: capacidades excepcionales, motivación y creatividad, así como factores ambientales: familia, escuela y amigos o personas en condiciones semejantes.

Otra importante aportación en la interacción entre talento innato y el medio ambiente es el presentado por Gardner (1995), quien desarrolla la teoría de las inteligencias múltiples, desafiando la noción de la inteligencia $g$ en la que se basan la mayoría de los modelos de prueba (test) de inteligencia. ${ }^{7}$

Señala que las personas poseen diferentes potenciales cognitivos, los cuales se desarrollan y manifiestan en la sociedad mediante la cultura y son resultado de la constante interacción entre factores biológicos y ambientales. Su propuesta acerca de la inteligencia se concentra en la existencia de siete tipos distintos de inteligencia, a saber:

1. Intrapersonal: metacognición y auto reflexión. 2. Interpersonal: capacidad para relacionarse con los demás. 3. Corporal: habilidad para controlar movimientos y producir objetos. 4. Verbal/lingüística: relacionada con el lenguaje oral y escrito, utilizada con exceso en el ámbito escolar.

5. Lógico/matemático: pensamiento científico; razonamiento inductivo/deductivo y manejo de números y patrones abstractos. 6. Visualespecial: capacidad para visualizar un objeto y crear imágenes mentales. 7. Musical: capacidad para reconocer sonidos, tonos, timbres, ritmos y formas musicales.

Desde la óptica multidimensional de Gardner se perfilan claramente los distintos campos del talento. Para tenerlo, es necesario destacar en una de las inteligencias, aunque las demás se posean en menor grado. Con el apoyo de la

\footnotetext{
${ }^{6}$ En el concepto de 'habilidad por encima del promedio' se incluyen las habilidades destacadas en dominios específicos que excedan del $5 \%$ al $10 \%$ del desempeño.

${ }^{7}$ Gardner (1995) define la inteligencia como una habilidad o un conjunto de habilidades que permiten al individuo resolver problemas o desarrollar productos, consecuencia de un determinado contexto cultural.
} 
teoría de Gardner, se puede considerar que la superdotación es resultado de las habilidades innatas en interacción con un medio ambiente adecuado y favorable.

\subsection{Definiciones orientadas a modelos cognitivos}

A este grupo pertenecen las definiciones que hacen referencia a procesos de pensamiento, memoria y otras habilidades, tales como los estudiados por Sternberg (1985) y Sternberg y Davidson (1986). Estos autores proponen un modelo triádico de inteligencia al considerar que la actuación de la intuición, las habilidades en la solución de problemas y los componentes de adquisición de conocimientos son indicadores de superdotación. El modelo incluye tres subteorías:

a) La subteoría contextual que describe qué tipos de conductas o situaciones pueden considerarse inteligentes en relación con las diferentes culturas e implica destrezas de solución de problemas y aptitudes sociales prácticas.

b) La subteoría experiencial indica que la inteligencia es relativa a la experiencia de cada sujeto y otorga especial relevancia el proceso de intuición.

c) La subteoría componencial aborda cuáles son los mecanismos de procesamiento de la información que se utilizan al realizar conductas inteligentes.

En función de estos aspectos, Sternberg (1985) diferencia tres tipos de talentos:

1. Analíticos que se caracterizan por la gran capacidad de planificación, por las altas puntuaciones en los test (pruebas) y en las calificaciones académicas destacadas.

2. Creativos, que son característicos de niñas, niños y personas muy dotadas, principalmente para la generación de nuevos planteamientos y para sintetizar de forma integrada la información.

3. Prácticos, característicos de las personas que destacan por su gran habilidad en el mundo social. ${ }^{8}$

\footnotetext{
${ }^{8}$ Sternberg (1985) sostiene que los niños y, en general, las personas talentosas demuestran un funcionamiento cognoscitivo cualitativamente diferente al de otros, en uno o más de los componentes de la inteligencia (metacognitivos de desempeño y/o de adquisición de información); igualmente, son expertos en su aplicación a situaciones nuevas y/o mecanismos de automatización frente a situaciones familiares. Por último, las personas con un alto nivel de habilidades prácticas suelen destacarse en una o más de las tres funciones u objetivos de la inteligencia (adaptación, selección y modificación del ambiente). En esta orientación se plantea que las niñas y los niños superdotados presentan diferencias en la calidad del procesamiento de la información, siendo superior a la de los niños promedio. Por ejemplo, su capacidad meta cognitiva comienza a una edad más temprana. Algunos proponen hablar de QI (quality information) para referirse a la calidad del procesamiento de la información.
} 
Por otra parte, Gagné (1993) desarrolla un modelo que se caracteriza por los siguientes rasgos: 1. Admite la existencia de capacidades y desempeños de excelencia en una amplia gama de dominios, 2 . Reconoce la intervención crítica de variables personales y ambientales en el desarrollo del talento, 3. Distingue conceptualmente los términos "talentoso" y "dotado" y 4. Propone criterios operacionales coherentes para definir la extensión del concepto, es decir su prevalencia en la población.

Gagné (1991) sugirió que la superdotación está asociada, la mayoría de las veces con la habilidad intelectual general, mientras que el talento denota destrezas o aptitudes más específicas. En la figura 1 se muestra el proceso de manifestación de los talentos, el cual transita de lo potencial a lo manifiesto; es decir, de aptitudes sobresalientes y potenciales, mediante un contexto facilitador, a campos de manifestación de los talentos.

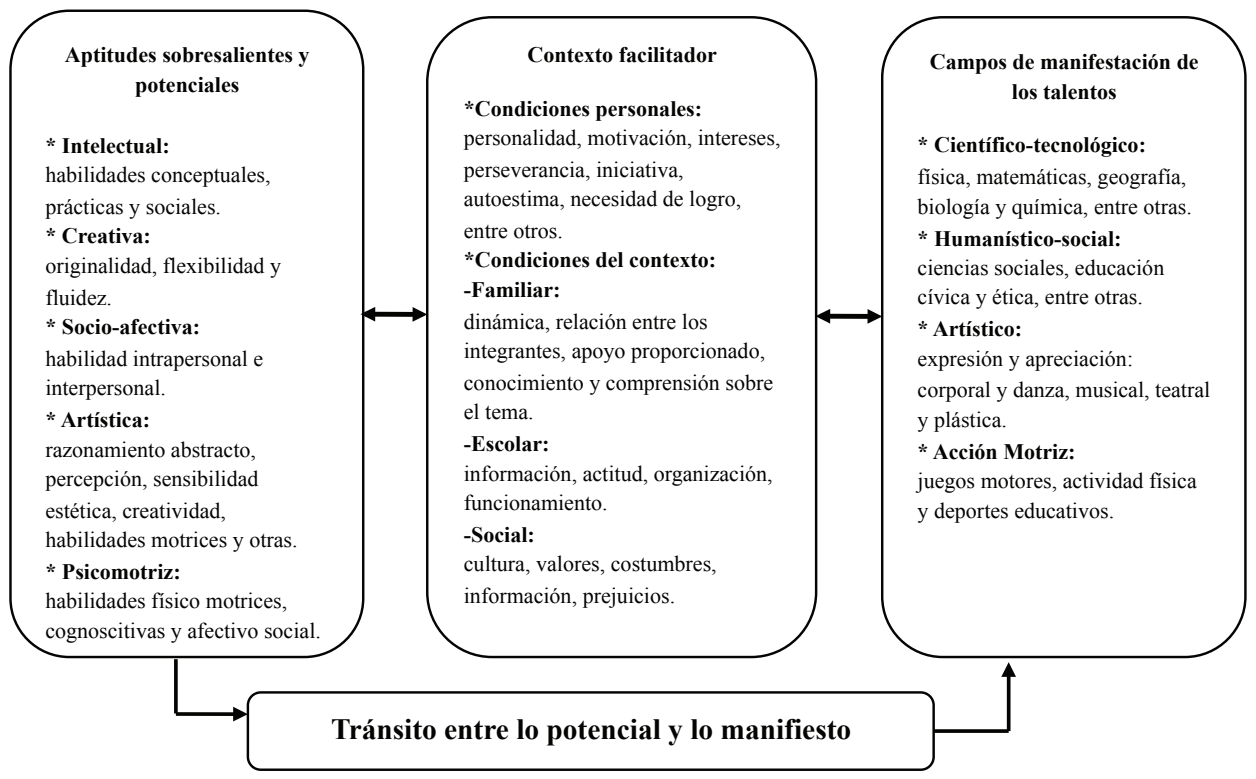

Fuente: adaptado de F. Gagné (1999).

Figura 1

Proceso de manifestación de los talentos

En el caso de la superdotación general, ésta se manifiesta en cinco dominios principales: intelectual, creativo, socioafectivo, artístico y psicomotriz. 
En el proceso de su evolución, a lo largo de los años escolares, niñas y niños desarrollan talentos específicos, mediatizados por la familia, la escuela, la personalidad, los intereses, las actitudes y la identificación con las experiencias. De lo anterior se desprende que el talento surgido de una habilidad específica, facilitará el aprendizaje y el desarrollo de una ocupación particular o de un dominio de ocupaciones.

\subsection{Definiciones orientadas a modelos sistémicos}

En este enfoque, Tannenbaum (2000) define la aproximación sistémica, la cual indica la forma en que la sociedad determina el individuo que es reconocido como talento y también considera que los logros destacados son determinados por cinco factores: 1. La habilidad general, 2. La habilidad específica, 3. Los factores no intelectuales, 4 . Los factores medioambientales y 5. Los factores del azar.

Mönks (2003) propuso que el talento de las personas, dado el enfoque del modelo sistémico está determinado por aspectos socioculturales y psicosociales; además considera que el desarrollo del talento depende de los responsables políticos, del periodo histórico y de una actitud general positiva frente al hiperdotado. Si la opinión pública y los responsables políticos no favorecen el estudio del talento y de la educación para hiperdotados, el niño hiperdotado puede no desarrollarse conforme a sus necesidades intelectuales y de crecimiento. ${ }^{9}$

\section{Sobre concepto de capital social}

\subsection{Antecedentes}

Desde hace algún tiempo el bienestar de una nación ha sido asociado en cierta medida con sus condiciones económicas, de manera que mientras mayores niveles de producción por persona combinados con un sistema distributivo adecuado tengan las sociedades, mejores niveles de vida tendrán

\footnotetext{
${ }^{9}$ Otro de los avances teóricos que ha tenido relevancia recientemente es la determinación de distintos niveles de talento. Desde esta perspectiva, Gagné (1993) propone utilizar un criterio estadístico basado en la desviación estándar de la distribución de los cocientes Intelectuales (ci), pero considerando también el error de medición de las pruebas (test) de ese CI, llegando a una clasificación de los niveles de dotación o talento, tales como: básico, moderado, alto y extremo.
} 
sus miembros. Por otro lado, el crecimiento de la producción por persona se ha atribuido a un aumento o mejoramiento en los factores que intervienen en ella: trabajo humano, capital manufacturado, materias primas naturales, tecnología o forma en que se combinan dichos factores, así como la manera en que se organiza el proceso productivo. Sin embargo, durante buen tiempo se consideró que el capital manufacturado era el factor más importante por ser el limitativo, ya que se consideraba que la población crecía de manera natural y los bienes de la naturaleza eran suficientemente abundantes, al tiempo que las mejores formas de producir dependían del ingenio de los humanos al interactuar con las herramientas. ${ }^{10}$

Esa creencia sufrió un cambio importante en la segunda mitad del siglo pasado, cuando se tuvo conciencia de que los bienes naturales no eran ilimitados ni fijos, sino que podían aumentar o disminuir dependiendo del trato que se les diera y de que los humanos podían aumentar su productividad a través de la educación, la capacitación o el entrenamiento. En ambos casos eran susceptibles de acumulación, de manera semejante al capital manufacturado, por lo que se les identificó como capital natural y capital humano, respectivamente. Pero aún así, se consideraba que los factores de la producción intervenían de manera individual en el proceso productivo; no se valoraban los efectos que en la producción tenía la interacción positiva entre ellos fuera de la actividad laboral, es decir, la cooperación social.

\subsection{El Capital Social}

Una revisión de la literatura muestra que la cooperación social es la base de lo que actualmente se conoce como capital social. ${ }^{11}$ De hecho, Pierre Bourdieu

\footnotetext{
${ }^{10}$ De hecho, esa creencia derivó en el florecimiento de la doctrina neoclásica del crecimiento económico, donde la pregunta central era: ¿qué hacer para que el capital de la economía crezca de manera que todos los trabajadores que se incorporen a la fuerza laboral puedan emplearse de la mejor manera en la sociedad? (Carrillo, Cerón y Reyes, 2007).

${ }^{11}$ En un recuento de los orígenes y evolución del significado del término 'capital social', López, et al. (2007) encuentran que pensadores del siglo xviII, incluidos David Ricardo y Adam Smith, fueron los primeros que consideraron el comportamiento social como coadyuvantes del comportamiento económico. Comentan que esa coadyuvancia de valores fue desestimada por los economistas posteriores a los clásicos pero fue retomada por la sociología, ya que parece existir unanimidad en que el contenido del término tiene sus raíces en el libro de Alexis de Tocqueville: La democracia en América (1835), “...quien observó en un viaje a América que una de las mayores diferencias entre los estadounidenses y los franceses era la predisposición de los primeros a ejercer el llamado "arte asociativo"... Los contactos sociales basados en las normas de reciprocidad y confianza hacían posible un mejor funcionamiento de la democracia en América".
} 
en su artículo "Le capital social", define al término como "...el agregado de recursos actuales...que están vinculados a la posesión o acceso a una red permanente de relaciones más o menos institucionalizadas de mutua aceptación y reconocimiento..." (Bourdieu, 1980). Por otro lado, James Coleman (1988) propuso que además de las relaciones sociales de mutua aceptación, el capital social también incluye la estructura social en la que los individuos están insertos. Así, Coleman define al capital social como: “...el valor que tienen para los actores aquellos aspectos de la estructura social, como los recursos que pueden utilizar para perseguir sus intereses" (Coleman, 1990: 305, citado por López, et al., 2007:1063).

De la definición de Bourdieu se desprende que el capital social se compone de dos elementos: la relación social, que permite a los individuos estar conectados mutuamente, y la calidad (y cantidad) de recursos que se acrecientan en los individuos gracias a esa construcción deliberada de sociabilidad, mientras que con Coleman, esos dos elementos se complementan con la estructura que permite que sucedan, y que les permite a todos los individuos beneficiarse de ella, aunque no hubieran participado en su construcción. ${ }^{12}$

No obstante lo anterior, algunos reconocen que la concepción más clara y operativa del término corresponde a Putnam (1993), quien concibe el capital social como una cualidad de los grupos que contribuyen al buen gobierno y al progreso económico, fundamentalmente gracias al grado de confianza y reciprocidad que existe entre los actores sociales, a las normas de comportamiento cívico practicadas y al nivel de asociatividad que caracteriza a la sociedad. De hecho, Putnam define al capital social como “...aspectos de la organización social, tales como la confianza, las normas y las redes, que pueden mejorar la eficiencia de una sociedad al facilitar la acción coordinada y la cooperación para el beneficio mutuo" (Putnam, 1993:67, citado por López, et al., 2007: 1064.)

\footnotetext{
${ }^{12}$ Según López, et al. (2007) desde la definición de Coleman, el capital social estaría caracterizado:

1. Por crearse en la estructura social

2. Por facilitar acciones tanto personales como colectivas para los individuos que están situados dentro de esa estructura

3. Por la existencia de una expectativa de reciprocidad por parte de quien hizo el favor y el establecimiento de una obligación de no quebrantar la confianza por parte de quien lo ha recibido

4. Por el establecimiento de una serie de normas y sanciones que regulan esas conductas (p. 1064).
} 
En ese sentido, para Putnam el capital social:

1. Se crea en las redes o contactos que se forman entre las personas o entre los grupos de personas y sin las cuales las sociedades no podrían organizarse ni funcionar.

2. Surge gracias a cuatro elementos fundamentales: compromiso cívico, reciprocidad, confianza y asociatividad.

3. Produce beneficios tanto para quien forma parte de la red, como para los individuos o grupos que sin estar en la red guardan cierta relación con ella.

A partir de estas concepciones del término, el capital social es un activo que está implícito en las relaciones sociales y puede ser promovido o restringido por dichas relaciones, pero debe reconocerse que el capital social no es sólo el conjunto de recursos que se hayan involucrados en las relaciones, sino también las normas y valores asociadas a dichas relaciones. En este sentido se pueden identificar dos formas generales que puede tomar el capital social: las obligaciones y expectativas de reciprocidad y las normas y sanciones efectivas; es decir, son las normas y valores compartidos los que promuevan la confianza y la cooperación social. De hecho, Fukuyama (2001) propone que la existencia pura de valores comunes no produce capital social, sino que además se requieren virtudes como honestidad, cumplimiento de obligaciones y reciprocidad.

\subsection{Las implicaciones del capital social}

Sobre las implicaciones del capital social en cuestiones operativas de la vida en comunidad, se tienen varios enfoques, a saber (López, et al. 2007: 1065-1066):

i) Los que centran su análisis en el capital social como estrategia alternativa para promover la equidad, usándolo como recurso y administrado correctamente. ${ }^{13}$

ii) Los que ven al capital social como un instrumento importante para incrementar el bienestar social y económico de un país o de una comunidad, promoviendo la confianza, la coordinación y la cooperación en todos los niveles. ${ }^{14}$

\footnotetext{
${ }^{13}$ Aquí, los autores citan, entre otros, a Siles et al. (1994), Banco Mundial (2002), Durston (2000).

${ }^{14}$ Las fuentes citadas por los autores en este caso, incluyen a Putnam (1993), Fukuyama (1995), Knack y Keefer (1997), Stiglitz (1998), Woolcock (1998), Dasgupta (2002).
} 
iii) Los que utilizan la noción de capital social en el área de las políticas sociales, argumentando que las comunidades con una sociedad civil vigorosa y un grado alto de participación quedan más satisfechas con su sistema democrático que las sociedades con niveles reducidos de participación cívica. ${ }^{15}$

iv) Los que consideran al capital social como generador de condiciones para un mejor intercambio de recursos entre empresas y sectores, así como para la creación de capital humano, el aprendizaje interorganizativo y la innovación de productos. ${ }^{16}$

Por otro lado, en cuanto al tipo de bien que representa el capital social, se tienen enfoques que lo consideran como un bien público (o comunitario) o como un bien privado. En el primer caso, se supone que el capital social radica en las estructuras normativas y sancionadoras de la sociedad, que contribuyen al beneficio del grupo, mientras que en el segundo lo consideran un recurso que reside en las relaciones entre personas como una característica individual: cada individuo tiene su propia red de contactos de la que obtiene beneficios sólo personales. ${ }^{17}$

\subsection{Otras consideraciones sobre el capital social}

De todo lo anterior se puede deducir que el capital social está directamente relacionado con la capacidad asociativa de la población, pero también con su capital manufacturado (infraestructura) y su capital humano. Por ello se puede esperar que mientras más afectividad y confianza exista entre los miembros de la sociedad, y mientras más creativos y productivos sean éstos, mayor será el capital social de la comunidad.

Albert O. Hirschman en El avance en colectividad: experimentos populares en América Latina, indica que el capital social “...a diferencia del capital físico y del capital natural, se incrementa con su uso, y también puede decrecer sustancialmente cuando no se usa..." (Hirschman, 1986).

Por ello, mientras mayores acuerdos y mejores conocimientos existan en la sociedad acerca de cómo hacer las cosas para no interferir con los demás,

\footnotetext{
${ }^{15}$ En este enfoque, los autores incluyen a Putnam (1993), Heliwell y Putnam (1995), Kliskberg (2000).

${ }^{16}$ Aquí, los autores citan, entre otros, a Burt (1992), Galán y Castro (2004), Adler y Kwon (2002).

${ }^{17}$ Entre quienes optan por considerarlo un bien comunitario, los autores identifican a Bourdieu (1986), Coleman (1990), Putnam (1993), Portes (1998), mientras quienes lo ven como un bien privado incluyen a Burt (1997), Leana y Van Buren (1999).
} 
y resolver los problemas en paz, se dice que existe más capital social. Y seguramente ésa es la razón por la cual desde el inicio de su estudio, allá por los años ochenta del siglo pasado, el capital social estuvo asociado con las teorías del desarrollo, al identificársele no sólo como un indicador de mejores condiciones de desarrollo de una nación, sino como un factor importante en su promoción.

\section{Caracteríticas generales del programa}

\subsection{Objetivos del programa}

De acuerdo con las Reglas de Operación publicadas el 31 de enero de 2011 en la Gaceta Oficial del Distrito Federal (2011), el objetivo general del Programa de Niñas y Niños Talento es: “Lograr que las niñas, niños y adolescentes sobresalientes tengan acceso a una formación integral, a través del desarrollo de sus habilidades artísticas, culturales, científicas y deportivas, con la finalidad de generar procesos de participación infantil y educación comunitaria".

Los objetivos específicos del programa, de acuerdo con esas reglas de operación, son:

1. Implantar un sistema de estímulos que permitan el desarrollo de los talentos de las niñas, los niños y adolescentes de 6-15 años de edad con un promedio mínimo de 9.0 de calificación, mediante la impartición de clases extraescolares en un marco de reconocimiento y estímulo permanente a su esfuerzo y dedicación.

2. Fomentar actitudes que estimulen la investigación y propiciar la innovación de nuevas metodologías para una buena intervención educativa.

3. Propiciar la formación de niñas, niños y adolescentes con principios de equidad de género, libertad y responsabilidad, la identidad cultural y la conciencia ecológica.

4. Acompañar el desarrollo de niñas, niños y adolescentes a lo largo de toda su formación.

5. Reconocer la dedicación y el esfuerzo de niñas, niños y adolescentes con mejores calificaciones.

6. Apoyar a niñas, niños y adolescentes en su formación y en el desarrollo de actividades diarias. 
Para lograr estos objetivos, el programa brinda:

1. Estímulos económicos de $\$ 1800.00$ anuales divididos en depósitos de \$150.00 mensuales, además de una cuenta adicional de 1200.00 pesos anuales el cual se fracciona en dos entregas de \$600.00: una en el mes de julio y la otra en diciembre.

2. Cursos extraescolares de áreas de artes, ciencias o deportes que se imparten en los centros del Sistema para el Desarrollo Integral de la Familia del Distrito Federal (DIF-DF), una vez a la semana, con una duración de una hora.

3. Visitas a centros culturales y deportivos.

\subsection{Operación del programa}

El DIF-DF, a través de la Dirección Ejecutiva de Niños Talento (DENT), se encarga de la operación del programa, es decir, de la impartición de las clases extraescolares, mientras que el Fideicomiso Educación Garantizada (FIDEGAR), a través de la Coordinación de Niños y Jóvenes Talento (CNJT), se encarga de la entrega de los estímulos económicos a los beneficiarios. Para recibir el estímulo, los beneficiarios deben cumplir los siguientes requisitos: a) Tener 6 años cumplidos y hasta los 15 años de edad. b) Tener un promedio mínimo de 9.0 de calificación. c) Habitar en el Distrito Federal. d) Estar inscritos en escuelas públicas en el Distrito Federal

En cuanto a la meta física, para el año 2014 el programa proyectó atender a una población objetivo de 120 mil beneficiarios en 55 centros del DIF-DF, donde se enfocan en fomentar su desarrollo, basados en un eje principal: la creatividad. Para ello el programa desarrolla actividades en tres áreas temáticas: artes, ciencia y deportes, que incluyen las siguientes disciplinas: música, artes plásticas, teatro, creación literaria y danza, en el área de las artes; computación, historia de México, física, matemáticas, inglés y biología, en el área de las ciencias, y natación, futbol y básquetbol, en el área de deportes. ${ }^{18}$

\footnotetext{
${ }^{18}$ De hecho, en diciembre de 2014, el $42.1 \%$ de los beneficiarios del programa se concentraban en el área de las ciencias, mientras otro $36.4 \%$ lo hacían en disciplinas de la cultura y el $21.5 \%$ restante, en deportes. (FIDEGAR, 2014).
} 


\subsection{Cobertura del programa}

El programa ha atendido, en promedio, a más de 100 mil beneficiarios durante cada uno de los ciclos escolares en los que ha operado, tal como se muestra en la gráfica 1, en donde se tiene que en el ciclo escolar 2013-2014, se atendieron 98 513, mientras que a septiembre de 2015, se habían atendido 95323 beneficiarios. Los recursos asignados al programa dependen del número de beneficiarios. Desde el inicio del programa en 2007 hasta esta fecha, el monto del apoyo por beneficiario ha sido de 3 mil pesos mexicanos al año.

\section{Gráfica 1}

Población beneficiaria del programa de Niñas y Niños Talento 2007-2015

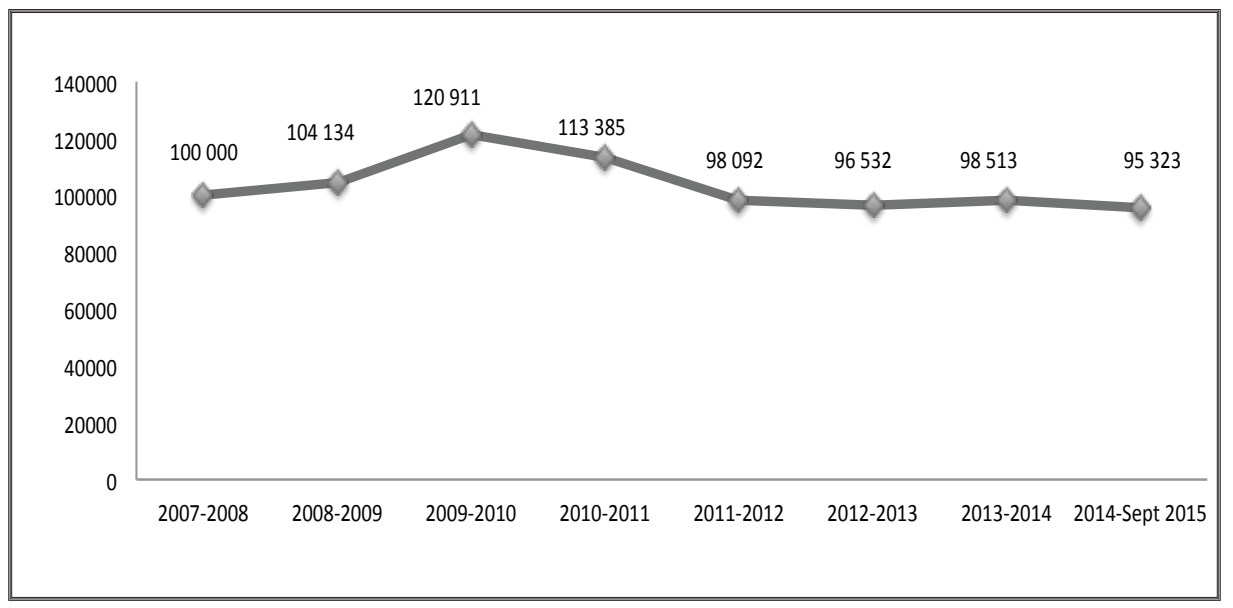

Fuente: Dirección de Evaluación del Fideicomiso Educación Garantizada con datos de la Dirección Ejecutiva de Niños Talento DIF-DF y de la Coordinación de Niños y Jóvenes Talento (FIDEGAR, 2015).

\subsection{Características de los beneficios del programa}

Programa ha logrado atender a su población objetivo desde el inicio de sus operaciones. En el ciclo escolar 2013-2014 atendió a 98 mil 513 beneficiarios, de los cuales el 58.0\% fueron niñas, mientras que el $42.0 \%$ fueron niños. En el caso de la distribución de los beneficiarios de acuerdo con 
la Delegación de residencia, se tiene que Iztapalapa concentra a casi una tercera parte de los menores (29\%), seguida de Gustavo A. Madero, con el $16 \%$, situación que coincide con las proporciones demográficas de la Ciudad y con los indicadores de vulnerabilidad (gráfica 2). Por otro lado, con respecto a las características socioeconómicas de los hogares de los beneficiarios del programa, se tiene que en 2010, el ingreso mensual aproximado del $40 \%$ de los hogares de los beneficiarios era de entre uno y dos salarios mínimos, seguido del $29.8 \%$ que oscilaba entre dos a tres salarios mínimos (gráfica 3). Al respecto, el 69.5\% de las familias tenían en ese año entre dos y cuatro personas miembros que dependían económicamente del jefe del hogar.

\section{Gráfica 2}

Distribución de beneficiarios por delegación

de residencia, diciembre de 2014

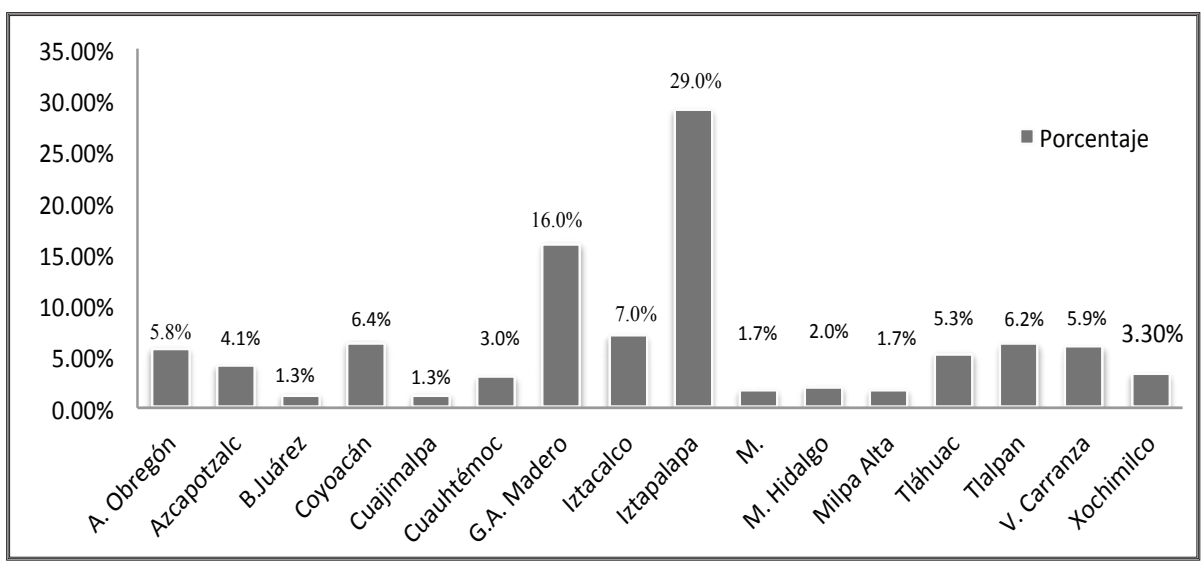

Fuente: Dirección de Evaluación del Fideicomiso Educación Garantizada con datos de la Dirección Ejecutiva de Niños Talento DIF-DF y de la Coordinación de Niños y Jóvenes Talento (FIDEGAR, 2015). 


\section{Gráfica 3}

Ingreso mensual aproximado de los hogares de los beneficiarios del programa, ciclo escolar 2009-2010

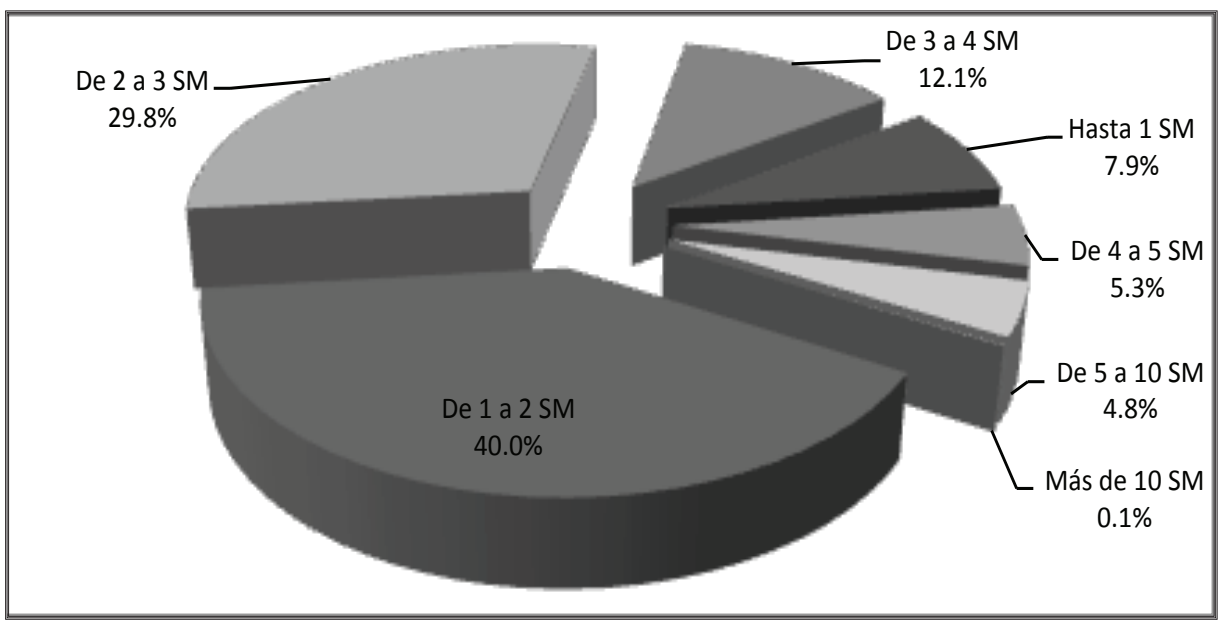

Fuente: Dirección de Evaluación del Fideicomiso Educación Garantizada, Encuesta a Padres de Familia de los Beneficiarios del Programa Niñ@s Talento ciclo escolar 2009-2010 (FIDEGAR, 2011).

\section{El análisis de impacto del programa social en la socioefectividad y en la creatividad de los beneficiarios}

\subsection{Estrategía metodológica}

El análisis de impacto tiene el objetivo central de dimensionar los resultados del programa en relación con las habilidades y aptitudes de los niños y las niñas talento que más se podrían relacionar con el capital social: su socio-afectividad y su creatividad. Por ello se decidió construir índices de socio-afectividad y de creatividad como componentes básicos del análisis, para luego dimensionar los factores que más influyen en la determinación de dichos índices, mediante la aplicación de un modelo econométrico diseñado específicamente para tal efecto.

La información utilizada para el ejercicio provino tanto de datos básicos proporcionados por el programa, como de dos encuestas levantadas entre 
2008 y 2010, a muestras de beneficiarios y de sus padres y madres. ${ }^{19} \mathrm{La}$ primera encuesta a los beneficiarios del programa fue realizada en julio de 2008, a 1115 padres y niños, mientras que la segunda encuesta a beneficiarios y familiares se realizó durante los meses de noviembre y diciembre de 2010, y fue aplicada a 1195 beneficiarios de los cerca de 100 mil que tenía el programa en esos años, y a 1021 padres o tutores.

La mayoría de los niños que contestaron la encuesta estaban inscritos en tercer y cuarto grado de primaria (49\%), mientras que los de segundo y quinto tuvieron participaciones más bajas (15 y 16\%), con los del primer año de primaria representando la menor proporción de alumnos del programa (1\%).

\subsection{Características de las mujeres}

En esta sección se describen las principales características de las muestras de beneficiarios y de familiares o tutores, a partir de la información proveniente de los instrumentos aplicados a ellos en las encuestas realizadas.

En la primera encuesta a familiares o tutores de beneficiarios del programa, se entrevistaron 1115 individuos, de los cuales sólo el 10\% eran hombres y el 90\%, mujeres. La mayoría de las mujeres (el 35\%) se encontraban en el rango de edad entre los 33 y 39 años; en segundo lugar, con 25\%

\footnotetext{
${ }^{19}$ El diseño de las muestras fue realizado con base en el número de beneficiarios del programa que asisten a las actividades extraescolares en cada uno de los centros DIF-DF en las 16 delegaciones del Distrito Federal. Se optó por un muestreo aleatorio estratificado, donde la población de $N$ unidades se divide en estratos $N_{1}+N_{2}+\ldots+N_{L}=N$, correspondientes a cada una de las 16 delegaciones del Distrito Federal. Además, se consideran sub-estratos $n_{1}+n_{2}+\ldots+n_{1}=n$, cuya representatividad se refiere a cada uno de los centros DIF-DF, que conforman la delegación $N_{i}$. Una vez seleccionados los estratos, se buscó extraer una muestra de cada uno de ellos, para lo cual fue necesario calcular el tamaño óptimo de la muestra para la población general. De esta forma, el tamaño óptimo de la muestra se obtiene por la ecuación $n=\left(Z^{2} \mathrm{PQ} / \mathrm{e}^{2}\right) /\left(1+(1 / \mathrm{N})\left(\left(\mathrm{Z}^{2} \mathrm{PQ} / \mathrm{e}^{2}\right)-1\right)\right)$, donde: $N$, representa la población total; $n$, indica el tamaño óptimo de la muestra; $z$, indica el nivel de significancia estadística (confianza) del 95\%, que indica dos desviaciones estándar; e, representa el error, el cual es igual a $0.03 ; P$, indica la proporción de población con una característica que se desea conocer. Se emplea el indicador de proporción de población más amplio, que no provoque sesgo, el cual es igual a $0.5(\mathrm{Q}=1-\mathrm{P})$. Por ello, la muestra se calculó considerando el siguiente escenario: 1 ) se supuso un nivel de confianza del $95 \%$, por lo que $\alpha=0.05$ y z $=1.96 \approx 2$ y 2 ) el número total de unidades de estudio $\left(N_{h}\right)$ fue de 100000 beneficiarios. El cálculo del tamaño de muestra fue de 1115 entrevistas a realizar entre beneficiarios y un igual número entre padres de familia del Programa. Dado que se propuso un muestreo estratificado, en cada estrato se debe analizar un número total de unidades de estudio $\left(N_{h}\right)$. El siguiente paso fue la estimación del tamaño óptimo de la muestra, dentro de cada estrato $\left(n_{h}\right)$. Considerando una ponderación por estrato, se calculó una afijación de la muestra $\left(W_{h}\right)$, que se presenta en la ecuación: $W_{k}=N_{h} / N$.
} 
se encontraba el rango de edad de 26 a 32 años y en tercer lugar, las mujeres en el rango de edad de 40 a 46 años. De los familiares entrevistados en la primera encuesta, la mayoría (el 61.7\%) reportaron estar casados; el 20.5\% vivían en unión libre, siguiendo el $8.8 \%$ que reportó ser madre soltera y sólo el $0.4 \%$ eran padres solteros.

En la segunda encuesta a familiares o tutores de beneficiarios se entrevistaron 1021 de ellos, los cuales mostraron una distribución semejante a la de los de la primera encuesta, donde el $10.6 \%$ eran hombres y el $89.4 \%$, mujeres. El 35.5\% de las madres de familia se encontraban en el rango de edad de 33 a 39 años; el 24.3\% se encontraban en el rango de edad de los 26 a los 32 años, y; el 20.1\% entre los 40 y 46 años. En esta encuesta, el 63.4\% reportaron ser casados, mientras que el 18.8\% vivían en unión libre; el 9.8\% reportaba ser madre soltera y el $0.4 \%$ eran padres solteros. El $6.9 \%$ de los familiares encuestados vivían separados.

En la primera encuesta a beneficiarios del programa, se consideraron 1115 de ellos, de los cuales el 43.5\% eran niños y el 56.5\% eran niñas. La mayoría de los beneficiarios en la muestra reportaron tener 8 años (23\%), siendo $13 \%$ niñas y $10 \%$ niños. En segundo lugar se encontraban, entre las niñas, la edad de 10 años (con un 11.3\%), y entre los niños, la edad de 9 años (con 9.1\%).

Con respecto al grado escolar se encontró que el $24.9 \%$ de los encuestados se encontraban en el tercer año de la primaria; en segundo lugar se encontraban los niños del cuarto año de primaria, con una participación del $21.5 \%$.

Ahora bien, en la segunda encuesta se incluyeron 1195 beneficiarios, de los cuales el $41.7 \%$ eran niños y el $58.3 \%$ eran niñas. La mayoría de las niñas en la muestra reportaron tener 9 años (el 14.3\%); de los niños, la mayoría se encontraba en los 8 años de edad (el 10.9\%). En el segundo lugar entre las niñas se encontraban los de 8 años de edad, con un $12.0 \%$ y después los de 10 años de edad, con un $10.2 \%$ de participación. Con respecto a los niños, en segundo lugar, con un $9.1 \%$ de participación estaban los de 9 años de edad y después, los de 10 años de edad, con un $7.1 \%$. Con respecto al grado escolar se encontró que el $26.5 \%$ de los encuestados se encontraban en el tercer año de la primaria, es decir, un $1.6 \%$ más que en la primera encuesta. En segundo lugar, se encontraban los niños del cuarto año de primaria con una participación del $22.5 \%$, lo que es un punto porcentual más que en la primera encuesta. 


\subsection{Instrumentos de campo}

Para efecto de las encuestas aplicadas, específicamente se diseñó una serie de instrumentos que contienen un listado de características relacionadas con habilidades intelectuales, creativas, socioafectivas, artísticas y psicomotrices, retomando parte del inventario para la identificación de las aptitudes sobresalientes propuesto por Zavala (2004). Sin embargo, para el caso que se reporta en este trabajo, se utilizó una pequeña muestra significativa de items en las áreas correspondientes a socio-afectividad y a creatividad. Específicamente, se trató de: 1) conocer aspectos de comportamiento clasificados como facilitadores (liderazgo, jovialidad, sensibilidad social, respeto, auto-control) y perturbadores (agresividad, apatía-retraimiento, ansiedad-timidez) en el desarrollo social intra e interpersonal y 2) apreciar la inteligencia creativa de niños y niñas a través de una evaluación cognoscitiva de la creatividad individual, en un contexto teórico de búsqueda y solución de problemas.

\section{Resultados del análisis de impacto del programa}

En este apartado se presentan primero los resultados del análisis del efecto del programa en el comportamiento socioafectivo de los beneficiarios, y luego los correspondientes a sus habilidades creativas.

\subsection{Efectos en el comportamiento socioefectivo}

La socioafectividad se refiere al marco social en el que se desenvuelve la persona, para ser favorecida en el proceso evolutivo de la capacidad sobresaliente. Renzulli (1986) considera la importancia de la interacción social de los compañeros, la escuela, la familia (considerados como factores ambientales) a su modelo de los tres anillos, como características ligadas a la superdotación (Rayo, 1997). Las personas con altos niveles de socioafectividad reaccionan emotivamente ante la interrupción de sus tareas en forma sistemática y activa, recuerdan más las tareas interrumpidas que las terminadas, reinician en forma más consistente las tareas inconclusas. Se fijan metas y actúan consistentemente para lograrlas ya que buscan, a través de la ejecución, su realización personal. Las interrupciones 
son una fuente de motivación para persistir, muestran una gran capacidad para relacionarse e interactuar con los demás y mantienen un equilibrio consigo mismos. ${ }^{20}$

Como ya se ha dicho, el instrumento de captación de información exploraba un conjunto de habilidades distintas; sin embargo, a fin de realizar un análisis más particular del impacto del programa sobre sus beneficiarios, se optó por crear un índice de socioafectividad que quedó representado sólo por algunos de los reactivos que se incluyeron en las dos aplicaciones del instrumento. En el cuadro 1 se muestran esos reactivos, según se refieren a todos los beneficiarios o en función del grado escolar que cursaban.

\section{Cuadro 1}

Distribución de los reactivos que miden socioafectividad

\begin{tabular}{|l|l|}
\hline A todos los beneficiarios & $\begin{array}{l}\text { me gusta jugar con mis amigos } \\
\text { me gusta conocer y jugar con nuevos niños (segunda } \\
\text { encuesta) } \\
\text { me gusta aprender con alguien que me explique lo que } \\
\text { tengo que hacer (segunda encuesta) } \\
\text { me gusta participar en voz alta cuando pregunta el pro- } \\
\text { fesor (segunda encuesta) }\end{array}$ \\
\hline $\begin{array}{l}\text { Sólo a beneficiarios de } 1^{\circ}, 2^{\circ} \\
\text { y } 3^{\circ} \text { de primaria }\end{array}$ & $\begin{array}{l}\text { me gusta probar cosas nuevas aunque me den un poco } \\
\text { de miedo } \\
\text { me gusta enseñarles lo que aprendo a mis compañeros } \\
\text { de clase }\end{array}$ \\
\hline $\begin{array}{l}\text { Sólo a beneficiarios de } 4^{\circ} \\
5^{\circ}, 6^{\circ} \text { de primaria y } 1^{\circ} \text { de } \\
\text { secundaria }\end{array}$ & me gustaría pasar algún tiempo en otra escuela \\
\hline
\end{tabular}

Fuente: primera y segunda encuesta a beneficiarios del programa Niñ@s Talento. Dirección de Evaluación del Fideicomiso Educación Garantizada (FICEGAR, 2011).

${ }^{20}$ Gardner distingue dos tipos de talentos sociales: intrapersonal e interpersonal. El primero se manifiesta cuando el niño(a) es consciente de sus emociones; sabe bien cómo expresar sus sentimientos y pensamientos; manifiesta una gran motivación intrínseca que le lleva a localizar y cumplir objetivos; establece y vive según un sistema de valores; le gusta trabajar independientemente; manifiesta curiosidad por las grandes interrogantes de la vida (significado, relevancia y finalidad) y le gusta indagar en las complejidades del ser humano. Mientras, el talento interpersonal es habilidad que muestran algunos alumnos para relacionarse con los demás de forma eficaz ya que poseen gran capacidad para discernir y responder de manera adecuada a los estados de ánimo, los temperamentos, las motivaciones y los deseos de otras personas; les gusta favorecer y mantener relaciones sociales; les encanta y tienen facilidad para participar en tareas cooperativas, asumiendo el papel de líder del grupo y suelen ser buenos mediadores sociales. 
Debido a que el índice de socioafectividad (IS) se eligió como uno de los factores asociados al talento, un aumento en los puntajes de la segunda aplicación del instrumento en comparación con los de la primera, estaría reportando mayores habilidades socioafectivas, lo que sería considerado como un impacto positivo del programa hacia sus beneficiarios. Los intervalos de puntuación para el IS calculado se determinaron de acuerdo con su media y su desviación estándar, y se consideraron tres categorías que son: $a$ ) bajo, que tomó valores de 1 a $4, b$ ) promedio, con valores de 5 a 7 y c) alto, que consideró valores de 8 a 10 (valor máximo del índice).

Los resultados de esta categorización indican que el $15.6 \%$ de niñas y niños talentosos se ubicaba por debajo de la media; que $60.5 \%$ de ellas y ellos presentaban un talento promedio y que un $23 \%$ poseía un talento superior a la media.

La fórmula general para determinar el valor del índice de socioafectividad (ecuación 1) es:

$$
I S=\sum_{j=J}^{N} X_{j}
$$

donde: $I S$, es el índice de socioafectividad; $N$, la población encuestada; $X_{j}$, un conjunto de variables de habilidades socioafectivas del elemento $j ; X$, variable de habilidades que pertenece al conjunto $X_{j}$.

Los datos obtenidos a partir de las encuestas revelan que más de la mitad de los niños encuestados presentan una conducta socio-afectiva positiva, situación que coincide con lo reportado antes (en la sección de consideraciones teóricas) en el sentido de que una de las características que distinguen a los niños con talento es la de tener un alto grado de socioafectividad.

Sin embargo, al comparar los resultados obtenidos de la primera y la segunda encuestas se observa un aumento de 10 puntos porcentuales en el índice de socio-afectividad de los niños. Dicha información puede atribuirse al hecho de que en los talleres extraescolares del programa: 1) se ofrecen ambientes y actividades variadas que estimulan a crear vínculos afectivos con los compañeros y demás personas con las que conviven los niños. 2) existen oportunidades para aprovechar las experiencias y aprender de ellas. 3) se trabaja con materiales educativos que refuerzan las áreas de interés y los temas que a los niños les gusta abordar.

En los siguientes apartados se presentan los resultados del análisis del comportamiento creativo de los beneficiarios del Programa, con base en la información proveniente de las encuestas. A través de esta información se 
obtienen datos que permiten aproximar el efecto que el Programa está teniendo en sus beneficiarios. ${ }^{21}$

\subsection{Eefectos en las habilidades creativas}

La creatividad puede concebirse como la capacidad de encontrar o inventar nuevas relaciones entre los elementos de la información ya conocida, o la creación de nuevos conceptos. La creatividad bajo la concepción Renzulliana supone que la actividad mental que envuelve la creatividad está presente en las niñas y en los niños en general, en la medida en que se hacen preguntas y dudan, tratan de adivinar y hacen suposiciones, cuando redefinen, ordenan y especulan sobre lo dicho.

La creatividad ha sido señalada con frecuencia como una de las características que distinguen a la población de niños y niñas sobresalientes. Se evidencia un alto nivel de creatividad por la independencia de pensamiento; la tendencia a la no conformidad; manifestación de opiniones contrarias a las habituales; capacidad de iniciativa; producción de trabajos útiles, vitales y sorprendentes; facilidad para aplicar conocimientos de una u otra materia o situación; originalidad, imaginación y fantasía en la organización de recursos; invención y construcción de aparatos con materiales sencillos; creación de ideas y procesos novedosos.

En un intento por medir la creatividad de los beneficiarios, se generó un índice de creatividad (IC) que fue elegido como uno de los factores asociados al talento y que resultaría útil para determinar el impacto del programa sobre sus beneficiarios. En este análisis se consideraron únicamente los datos obtenidos en la segunda aplicación del instrumento de captación de información, con el grupo de reactivos que se muestran en el cuadro 2.

La fórmula empleada para obtener el índice de creatividad (ecuación 2) es la siguiente:

$$
I C=\sum_{i=I}^{N} X_{i}
$$

donde: $I C$, es el índice de creatividad; $N$, la población encuestada; $X_{i}$, un conjunto de variables de habilidades creativas del elemento $i$; $X$, variable de habilidad que pertenece al conjunto $X_{i}$.

\footnotetext{
${ }^{21}$ Cabe señalar que si bien se retoma el modelo diferenciado de superdotación y talento propuesto por Gagné (1997), en este documento sólo se analizan dos determinantes del talento: comportamiento socioafectivo y habilidades creativas. Ésto, debido a que los instrumentos aplicados a los beneficiarios arrojaron información para estos rubros, que dicho sea de paso, son los más importantes.
} 


\section{Cuadro 2}

Distribución de reactivos que indican creatividad

\begin{tabular}{|l|l|}
\hline A todos los beneficiarios & $\begin{array}{l}\text { yo hago muchas preguntas } \\
\text { me gusta que a veces se cambien las reglas de un juego } \\
\text { me gusta hacer cosas difíciles } \\
\text { me gusta desarmar cosas para ver cómo funcionan } \\
\text { me gustan las historias o leyendas de hace mucho } \\
\text { tiempo } \\
\text { reviso cuidadosamente mi tarea antes de entregarla } \\
\text { cuanto más difícil es la tarea, más interesante }\end{array}$ \\
\hline $\begin{array}{l}\text { Sólo a beneficiarios de } 1^{\circ}, 2^{\circ} \\
\text { y } 3^{\circ} \text { de primaria }\end{array}$ & $\begin{array}{l}\text { me gusta coleccionar muchas cosas } \\
\text { jugar a imaginar cosas es muy divertido } \\
\text { me gusta aprender por medio de juegos }\end{array}$ \\
\hline $\begin{array}{l}\text { Sólo a beneficiarios de } 4^{\circ}, \\
5^{\circ}, 6^{\circ} \text { de primaria y } 1^{\circ} \text { de } \\
\text { secundaria }\end{array}$ & $\begin{array}{l}\text { me gusta hacer mis propios experimentos en ciencias } \\
\text { me gusta leer cosas sobre el futuro }\end{array}$ \\
\hline
\end{tabular}

Fuente: segunda encuesta a beneficiarios del programa Niñ@s Talento. Dirección de Evaluación del Fideicomiso Educación Garantizada (FIDEGAR, 2011).

Como en el caso del comportamiento socioafectivo, en el de las habilidades creativas los beneficiarios se categorizaron de acuerdo con el puntaje del índice de creatividad, considerando tres categorías: $a$ ) bajo, que tomó valores de 1 a $4, b$ ) promedio, con valores de 5 a 7 y $d$ ) alto, que consideró valores de 8 a 10 (valor máximo del índice).

Así, sólo un $12.1 \%$ quedó categorizado como niña o niño con talento por debajo de la media; un $71.1 \%$ alcanzó la categoría de niño (niña) talento promedio y un $16.5 \%$ se ubicó entre los niños con talento superior a la media. ${ }^{22}$ En los siguientes apartados se presenta el análisis econométrico de los determinantes de los índices de socioafectividad y de creatividad, para tratar de detectar el impacto del programa en esos dos tipos de comportamiento de sus beneficiarios.

${ }^{22}$ Contemplando que los reactivos determinados para medir el índice de creatividad fueron 10 en el caso de niñas y niños de $1^{\circ}, 2^{\circ}$ y $3^{\circ}$ de primaria y nueve para niñas y niños de $4^{\circ}, 5^{\circ}, 6^{\circ}$ de primaria y $1^{\circ}$ de secundaria, se consideró que por debajo de la media se ubicaría a los beneficiarios que contestaron menos de cinco items positivamente, y por arriba de la media a los que contestaron positivamente a más de ocho reactivos. 


\subsection{Análisis econométrico de la socioefectividad y la creatividad}

Se realizaron análisis econométricos de los índices de socioafectividad y de creatividad que permitieron analizar los factores que determinan la probabilidad del impacto del programa sobre los beneficiarios para que éstos tuvieran niveles de socioafectividad y de creatividad inferiores, iguales o superiores al promedio. El modelo econométrico empleado en ambos casos es un logit ordenado, el cual está determinado por las características de las variables dependientes correspondientes. ${ }^{23}$

La socioafectividad o la creatividad reportadas por los beneficiarios del programa se expresan como variables ordinales categóricas (latentes). Se considera que la escala en la que los beneficiarios se encuentran está compuesta por $J+1$ niveles:

a) la categoría 1 indica que el beneficiario tiene niveles de socioafectividad o de creatividad menores al promedio de los beneficiarios del programa $\left(H_{i 1}=1\right.$, si $\left.H_{i}^{*}<\propto_{1}\right)$,

b) la categoría 2 refiere al beneficiario con niveles iguales al promedio $\left(H_{i 2}=2\right.$, si $\left.\propto_{1}<H_{i}^{*}<\propto_{2}\right)$,

c) la categoría 3 indica al beneficiario con niveles superiores al promedio $\left(H_{i 3}=3\right.$, si $\left.\propto_{2}<H_{i}^{*} \propto_{3}\right)$.

El vector $\propto_{1}, \propto_{2}, \ldots, \propto_{(M-1)}$ indica los parámetros de impactos en la socioafectividad y en la creatividad de los beneficiarios del programa (a ser estimados en el modelo) que dividen su recorrido en intervalos asociados con las distintas puntuaciones de esas dos habilidades. Existe una correspondencia entre el orden de los valores de la variable real y el orden de la variable latente, es decir $H_{i}<H_{j}$. El modelo de respuesta múltiple se expresa formalmente a través de la ecuación (3):

$$
H_{t}^{*}=F\left(X_{t}+\mu_{t}=X_{t} \beta+\mu_{t}\right)
$$

\footnotetext{
${ }^{23}$ Los modelos logit ordenados se emplean cuando la variable dependiente es una variable de respuesta discreta ordenada (Green, 2002; Colin y Trivendi, 2005). El enfoque teórico de este tipo de modelos se fundamenta en la teoría de la utilidad del agente económico. Se supone que el agente económico es racional y que elige la alternativa u opción que le brinde una mayor utilidad. Además, el modelo se puede concebir como un problema de decisión, en el sentido de que se debe elegir una opción entre el conjunto de $M$ alternativas posibles.
} 
donde: $H_{t}^{*}$, es la variable latente categórica de socioafectividad o de creatividad de los beneficiarios del programa; $X_{t} \beta$, representa la combinación lineal de las variables exógenas del modelo y $F(\cdot)$ indica la función de distribución logística. La probabilidad de elegir cada una de las categorías de $Y_{t}$, está definida por las relaciones que se muestran en la ecuación (4):

$$
\begin{aligned}
& \operatorname{Prob}\left(Y_{t}=0 / X_{t}, \beta, \gamma\right)=\Lambda\left(\gamma_{1}-X_{t}, \beta\right) \\
& \operatorname{Prob}\left(Y_{t}=1 / X_{t}, \beta, \gamma\right)=\Lambda\left(\gamma_{2}-X_{t}, \beta\right)-\Lambda\left(\gamma_{1}-X_{t}, \beta\right) \\
& \operatorname{Prob}\left(Y_{t}=2 / X_{t}, \beta, \gamma\right)=\Lambda\left(\gamma_{2}-X_{t}, \beta\right)-\Lambda\left(\gamma_{2}-X_{t}, \beta\right) \\
& \operatorname{Prob}\left(Y_{t}=M-1 / X_{t}, \beta, \gamma\right)=\Lambda\left(\gamma_{(M-1)}-X_{t}, \beta\right)-\Lambda\left(\gamma_{(M-2)}-X_{t}, \beta\right)
\end{aligned}
$$

donde $\Lambda(\cdot)$ es una función de distribución para los modelos logit ordenados. Los valores de los umbrales o barreras y los valores de $\beta$ se estiman conjuntamente mediante la maximización del logaritmo de la función de verosimilitud (ecuación 5).

$$
\begin{gathered}
L(\beta, \gamma)=\sum_{\gamma=0} \log \left[\operatorname{Prob}\left(Y_{t}=0 / X_{t}, \beta, \gamma\right)\right]+\sum_{\gamma=1} \log \left[\operatorname{Prob}\left(Y_{t}=1 / X_{t}, \beta, \gamma\right)\right]+ \\
\ldots+\sum_{\gamma=(M-1)} \log \left[\operatorname{Prob}\left(Y_{t}=(M-1) / X_{t}, \beta, \gamma\right)\right]
\end{gathered}
$$

Los estimadores obtenidos por el proceso de máxima verosimilitud son consistentes y asintóticamente eficientes. El signo de los coeficientes muestra la dirección del cambio en la probabilidad de pertenecer a la categoría de respuesta más elevada debido a un incremento en la correspondiente variable explicativa. El efecto marginal del modelo logit ordenado, que permite estimar el impacto de las variables de control sobre la socioafectividad o la creatividad, está dado por la ecuación (6):

$$
\begin{aligned}
& \frac{\partial \operatorname{Prob}\left(Y_{t}=0\right)}{\partial X_{t}}=-\lambda\left(\gamma_{0}-X_{t} \beta\right) \beta_{k} \\
& \frac{\partial \operatorname{Prob}\left(Y_{\mathrm{t}}=1\right)}{\partial \mathrm{X}_{\mathrm{t}}}=-\lambda\left(\gamma_{1}-\mathrm{X}_{\mathrm{t}} \beta\right) \beta_{\mathrm{k}} \\
& \frac{\partial \operatorname{Prob}\left(\mathrm{Y}_{\mathrm{t}}=2\right)}{\partial \mathrm{X}_{\mathrm{t}}}=-\lambda\left(\gamma_{2}-\mathrm{X}_{\mathrm{t}} \beta\right) \beta_{\mathrm{k}}
\end{aligned}
$$




\subsection{Resultados del análisis econométrico de la socioefectividad}

En el cuadro 3, se muestran los resultados de las estimaciones del modelo logit ordenado donde se utilizó el índice de socioafectividad (IS) como la variable endógena. Como se recordará, el IS está integrado por tres categorías. La categoría 1 indica que el beneficiario tiene niveles en el índice respectivo menores al promedio de los beneficiarios del programa; la categoría 2 indica que el beneficiario tiene niveles en el índice respectivo iguales al promedio de los beneficiarios del programa y la categoría 3 indica que el beneficiario tiene niveles en el índice respectivo, superiores al promedio de los beneficiarios del programa.

Las variables independientes que tratan de explicar el efecto en el IS fueron: la edad de los beneficiarios, el sexo, el estado civil de los padres, la condición económica del hogar, la existencia de algún miembro destacado en el hogar, la escolaridad de la madre y la calificación que otorgan los beneficiarios al profesor con el cual toman los cursos. ${ }^{24}$

Además, se incluyeron tres variables que miden la asistencia por tipo de clase de los beneficiarios. La primera variable es la asistencia a clases deportivas: natación, futbol y basquetbol; la segunda es la asistencia a clases culturales: música, artes plásticas, teatro, creación literaria, y; finalmente, la asistencia a clases en ciencias como historia de México, física, matemáticas y biología. Debido a que la asistencia a estas clases fueron variables dicotómicas, se tomó como categoría base la asistencia a clases de cómputo e inglés.

De los resultados anteriores se puede inferir que conforme aumenta la edad de los beneficiarios, disminuye en $29 \%$ la probabilidad de que pasen

\footnotetext{
${ }^{24}$ Para analizar la influencia de condición económica de la familia en la creatividad de los beneficiarios del programa, se creó un índice socioeconómico (que se aprovechó tanto en el análisis del comportamiento socioafectivo como en el de habilidades creativas) con base en cinco reactivos de la segunda encuesta a familiares de las niñas y los niños talento. Estos reactivos fueron: $a$ ) el hogar cuenta con línea telefónica; $b$ ) El hogar cuenta con al menos un teléfono móvil; c) El hogar cuenta con televisión; d) El hogar cuenta con internet; e) El hogar cuenta con automóvil. De esta manera, el índice toma valores que van de 0 a 5 . Según la encuesta, el 38\% de los hogares de la muestra contaba con al menos un servicio; el $28 \%$, contaba con dos servicios; el $16 \%$, contaba con tres servicios; el $6 \%$ contaba con cuatro servicios, y; solo el 3\% contaba con los cinco servicios. El 9\% de los entrevistados argumentaron que en su hogar no había ninguno de los servicios incluidos en el índice. Es importante mencionar que éste índice fue considerado sobre la base de un estudio realizado por Scott (2004), donde encuentra evidencia de que en el ámbito educativo de sostenimiento público, los programas sociales tradicionales son aprovechados en mayor medida por quienes se encuentran en mejores condiciones económicas.
} 
al siguiente nivel superior del índice de socioafectividad. Este resultado debe ser interpretado con cuidado ya que no está claro por qué al aumentar la edad pueda disminuir la probabilidad de alcanzar un nivel más alto en el IS. Una interpretación más acorde para el signo de esta variable sugiere que a medida que el programa intervenga en edades más tempranas será más efectivo. Esta idea coincide con la de algunos especialistas que insisten en la importancia que tiene la identificación temprana de los niños que muestren "buenas" características para ser desarrolladas (Johnsen, 2004).

\section{Cuadro 3}

Modelo logit ordenado para explicar el efecto en el índice de socioafectividad

\begin{tabular}{lcc}
\hline \hline \multicolumn{1}{c}{ Variables exógenas } & $\begin{array}{c}\text { Variable endógena: índice de } \\
\text { socioafectividad } \\
\text { segunda encuesta }\end{array}$ \\
\hline \hline edad & -0.290 & $(3.07)^{*}$ \\
sexo & 0.102 & $(0.76)$ \\
estado civil & 0.100 & $(2.25)^{*}$ \\
condición económica & $-8.68 \mathrm{e}-06$ & $(0.37)$ \\
miembro del hogar destacado & -0.439 & $(2.18)^{*}$ \\
escolaridad de la madre & 0.005 & $(0.10)$ \\
calificación al profesor & 0.162 & $(1.74)^{+}$ \\
asistencia a clases deportivas & -0.066 & $(0.43)$ \\
asistencia a clases culturales & 0.221 & $(0.95)$ \\
asistencia a clases de ciencias & 0.629 & $(2.35)^{*}$ \\
observaciones & 1072 & \\
$\mathrm{R}^{2}$ & 0.042 & \\
\hline
\end{tabular}

Nota: los valores absolutos del estadístico z están entre paréntesis

+ Significativo al 10\%; ** Significativo al 1\%; ${ }^{*}$ significativo al 5\%;

Fuente: segunda encuesta a beneficiarios del programa Niñ@s Talento. Dirección de

Evaluación. Fideicomiso Educación Garantizada (FIDEGAR, 2011).

Con respecto al estado civil que tienen los padres de los beneficiarios, se puede concluir que el hecho de vivir en familias integradas aumenta en $10 \%$ la probabilidad de que los beneficiarios alcancen un nivel más alto en su IS. Respecto a esta variable, también hay coincidencia entre los especialistas en la materia de que los padres, hermanos y otros familiares juegan un papel importante en el desarrollo de las habilidades mostradas por las niñas y los 
niños, ya que son los padres y otros familiares quienes tienen contacto directo con ellas y ellos y quienes pueden asistirles en el proceso de desarrollo de sus habilidades, mediante las actividades que desarrollen dentro y fuera de la escuela (Johnsen, 2004).

Otra variable que es importante mencionar es la que se refiere a que se haya detectado algún miembro destacado diferente al beneficiario en el interior del hogar. Esta variable impacta negativamente en un $44 \%$ la probabilidad de que los beneficiarios alcancen un mayor nivel del IS de los beneficiarios. Finalmente, se encontró que la asistencia por parte de los beneficiarios a las clases de materias como historia de México, física, matemáticas y biología aumenta un 63\% la probabilidad de que las niñas y los niños se ubiquen en un nivel más alto del IS. Este resultado de ninguna forma significa que las otras clases no estén ayudando a los fines del programa. Por el contrario, las actividades culturales, deportivas, de cómputo e inglés que ofrece el programa son parte fundamental para detectar habilidades en los beneficiarios que dentro del salón de clases serían difíciles de detectar (Johnsen, 2004). ${ }^{25}$

\subsection{Resultados del análisis econométricos de la creatividad}

En el cuadro 4, se presentan los resultados de las estimaciones del modelo logit ordenado para el índice de creatividad (IC). En este caso, la variable dependiente es el índice que mide exclusivamente la creatividad en los niños y (como en el caso del comportamiento socioafectivo) está formado por tres categorías. La categoría 1 indica que el beneficiario tiene niveles de creatividad menores al promedio de los beneficiarios del programa; la categoría 2 indica que el beneficiario tiene niveles de creatividad iguales al promedio de los beneficiarios del programa y la categoría 3 indica que el beneficiario tiene niveles de creatividad superiores al promedio de los beneficiarios del programa. ${ }^{26}$

\footnotetext{
${ }^{25}$ La variable "calificación al profesor" resultó positiva pero con baja significancia estadística (10\%), e indica que niveles más altos de socioafectividad están asociados con alumnos que califican mejor a sus profesores.

${ }^{26}$ Las variables independientes que tratan de explicar el efecto en el índice de creatividad fueron las mismas que se consideraron en el caso del análisis del comportamiento socioafectivo: la edad de los beneficiarios, el género, el estado civil de los padres, la condición económica del hogar, la existencia de algún miembro destacado en el hogar, la escolaridad de la madre y la calificación que otorgan los beneficiarios al profesor con el cual toman los cursos, además de las tres variables que miden la asistencia por tipo de clase de los beneficiarios.
} 
Cuadro 4

Modelo logit ordenado para explicar el efecto en el índice de creatividad

\begin{tabular}{|c|c|c|}
\hline \multirow[t]{2}{*}{ Variables exógenas } & \multicolumn{2}{|c|}{$\begin{array}{l}\text { Variable endógena: índice de } \\
\text { creatividad segunda encuesta }\end{array}$} \\
\hline & Coeficiente & Valor de $z$ \\
\hline edad & -0.192 & $(3.77)^{* *}$ \\
\hline sexo & -0.006 & $(0.06)$ \\
\hline estado civil & 0.117 & $(2.62)^{* *}$ \\
\hline condición económica & -0.00001 & $(0.78)$ \\
\hline miembro del hogar destacado & -0.315 & $(1.45)$ \\
\hline escolaridad de la madre & 0.043 & $(0.84)$ \\
\hline calificación al profesor & 0.062 & $(1.65)^{+}$ \\
\hline asistencia a clases deportivas & 0.136 & $(1.59)$ \\
\hline asistencia a clases culturales & 0.138 & $(0.64)$ \\
\hline asistencia a clase de ciencias & 0.534 & $(3.47)^{* *}$ \\
\hline observaciones & 1072 & \\
\hline $\mathrm{R}^{2}$ & 0.0215 & \\
\hline
\end{tabular}

Nota: los valores absolutos del estadístico z están en paréntesis

+ significativo al $10 \%$; ${ }^{* *}$ significativo al $1 \%$; ${ }^{*}$ significativo al $5 \%$;

Fuente: segunda encuesta a beneficiarios del programa Niñ@s Talento. Dirección de

Evaluación. Fideicomiso Educación Garantizada (FIDEGAR, 2011).

Para el índice de creatividad, se observa que a medida que aumenta la edad de los beneficiarios, disminuye en 19\% la probabilidad de que alcancen un nivel más alto en el índice. Igual que en el caso de la socioafectividad, el signo para la variable edad sugiere que el programa será más efectivo en la medida que se intervenga a edades más tempranas. Respecto al estado civil que tienen los padres de los beneficiarios, se puede decir que el hecho de vivir con familias integradas aumenta en $12 \%$ la probabilidad de que los beneficiarios alcancen un nivel más alto en su índice de creatividad. Finalmente, también se encontró que la asistencia por parte de los beneficiarios a las clases de materias como historia de México, física, matemáticas y biología aumenta en 53\% la 
probabilidad de que los niños se ubiquen en un nivel más alto en su índice de creatividad. ${ }^{27}$

\section{Resumen y consideraciones fananciales}

Como se dijo al inicio de este trabajo, su objetivo es presentar los resultados de un análisis del impacto del programa de Niñas y Niños Talento en dos variables relacionadas con el capital social: la socioafectividad y la creatividad de los educandos. En las secciones anteriores se presentaron las características más destacables del programa así como su fundamento teórico, además de la metodología y los resultados del análisis de esos impactos.

Para estimar el impacto del Programa en el desarrollo de habilidades de las niñas y los niños, se utilizaron un conjunto de reactivos que exploraban diversas habilidades, destacando entre ellas las de tipo creativo y socioafectivo.

Con esa información, se construyeron índices de socioafectividad y de creatividad, con las que se clasificaron las niñas y los niños talento, dependiendo de si el valor del índice para ellos se ubicaba por encima o por debajo del valor medio, encontrándose que más del $60 \%$ de los beneficiarios se perciben con habilidades socio-afectivas positivas, debido muy probablemente a que en los talleres extraescolares del programa se ofrecen ambientes y actividades variadas que estimulan a crear vínculos afectivos con los compañeros y demás personas con las que conviven.

Por otro lado, a partir de los datos obtenidos en los índices de creatividad de las niñas y los niños encuestados, se encontró que un $15.6 \%$ de ellos quedaron ubicados por debajo de la media; $60.5 \%$ se ubicaron como niños con talento promedio y un $23 \%$ se clasificó con un talento superior a la media.

Un análisis más a fondo de los índices de socioafectividad y creatividad realizado con la ayuda de un modelo econométrico del tipo logit ordenado,

\footnotetext{
${ }^{27}$ Como en el caso del índice de socioafectividad, la 'calificación al profesor' fue positiva y significativa (al 10\%) en el caso del índice de creatividad, aunque en esta ocasión resultó menos impactante. Es importante mencionar que existe un debate importante acerca de la interpretación que debe darse a los coeficientes obtenidos en este tipo de ejercicios econométricos. Por un lado, la interpretación generalizada es la que se mencionó anteriormente. Por otro lado, hay quienes sugieren que la interpretación de los coeficientes sólo debe darse en el sentido del signo que se obtenga en los coeficientes, sin importar el valor del coeficiente. Independientemente de la preferencia sobre cómo se quieran interpretar los coeficientes, en términos de su signo o de su signo y su magnitud, lo cierto es que en ambos casos los resultados encontrados fueron semejantes.
} 
en el que se consideraron como variables independientes la edad de los beneficiarios, su género, el estado civil de sus padres, la condición económica del hogar, la existencia de algún miembro destacado en el hogar, la escolaridad de la madre, la calificación que otorgan los beneficiarios al profesor con quien toman los cursos y el tipo de clases a las que asisten los beneficiarios (artísticas, deportivas o de conocimientos científicos), mostró que: a) a medida que las niñas y los niños tienen mayor edad, disminuye la probabilidad de que pasen al siguiente nivel superior de cualquiera de los dos índices, $b$ ) aumenta la probabilidad de que los beneficiarios alcancen un nivel mayor en los índices en los casos en los que los niños viven en familias integradas y c) los niños que asisten a las clases de materias de ciencias (física, matemáticas y biología) aumentan considerablemente la probabilidad de ubicarse en un nivel más alto dentro del índice de creatividad.

En la medida en que esos resultados reflejaran realmente los impactos del programa, se podrían hacer algunas sugerencias para su mejora que incluirían: a) detectar las habilidades de los beneficiarios en la edad más temprana posible, pues si esto se cumple, la probabilidad de éxito en el desarrollo del talento será mayor, $b$ ) buscar el acompañamiento de los padres y otros familiares en las actividades que ofrece a sus beneficiarios y c) mantener la variedad de temas en las actividades extraescolares a fin de detectar habilidades que difícilmente podrían observarse en el salón normal de clases.

Por otro lado, en la medida en que continúe ofreciendo una educación de calidad a través de cursos especializados en las áreas de los talentos revelados de los educandos en entornos propicios para fomentar la socioafectividad y la confianza de ellos hacia los grupos sociales con los que interactúan de manera cotidiana, así como sus habilidades creativas, el programa estará fomentando su capacidad potencial para generar mayores ingresos familiares y también mayores niveles de asociatividad entre la población, tan importante en la definición del capital social de la comunidad. 


\section{Referencias}

Adler, P. S. y S. Kwon (2002). "Social Capital: Prospects for a New Concept". Academy of Management Review, 27(1): 17-40.

Alegre, O. (2000). Diversidad humana y educación. Ed. Aljibe. Málaga, pp. 133-170.

Alonso, F. (1996). El talento creador: rasgos y perfiles del genio. Ediciones Temas de Hoy, S. A., Madrid, España, pp. 120-140.

Alonso, J. y Y. Benito (1996). Superdotados: adaptación escolar y social en secundaria. Editorial Narcea. Madrid, España. pp. 89-140.

Álvarez, M. y R. Bisquerra (1996). Manual de orientación y tutoría. Ed. Praxis. Barcelona, España, pp. 47-99.

Banco Mundial (2002). Educación en América Latina y el Caribe. Washington, D.C., pp. 65-99.

Benito, Y. (1996). Inteligencia y algunos factores de personalidad en superdotados. Editorial Amarú. Salamanca, España, pp. 140-180.

Bourdieu, P. (1980). "Le capital social", Actes de la Recherche en Sciences Sociales, núm. 31, pp. 2-3. (1986). "The Forms of Capital". J.G. Richardson (ed.) Handbook of Theory and Research in Sociology of Education. New York: Greenwood, pp. 241-258.

Burt, R. (1992). "The Social Structure of Competition". En Nohria and Eccles (eds.) Networks and Organizations Structure, Form and Action. Boston, Massachusets: Harvard Business School Press, pp. 57-82. (1997). "The Contingent Value of Social Capital". Administrative Science Quarterly, 42 (2): 337-365.

Carrillo-Huerta, M. Mario, J. Arturo Cerón-Vargas y Miguel S. Reyes-Hernández (2007). Análisis del crecimiento económico. México, DF: Instituto Politécnico Nacional, pp. 70-122.

Coleman, J. S. (1988). "Social Capital in the Creation of' Human Capital". American Journal of Sociology, 94 (Special Supplement), pp. 95-120. (1990). Foundations of Social Theory. Cambridge, Massachusets: Harvard University Press, pp. 88-120.

Colin-Cameron, A. y Pravin K. Trivendi (2005). Microeconometrics. Methods and Applications. Cambridge University Press, New York, pp. 88-133.

Dasgupta, P. (2002). Social Capital and Economic Performance: Analytics. University of Cambridge and Beijer International Institute of Ecological Economics. Stockholm, pp. 110-140.

Durston, J. (2000). ¿Qué es el capital social comunitario? CEPAL. Serie Políticas Sociales, núm. 38. Santiago de Chile, pp. 90-131. 
Ebrard-Casaubon, Marcelo L., Mariagna Prats-Donovan y Mario M. Carrillo-Huerta (2009). Hacia una educación de calidad en la Ciudad de México. El programa Niños Talento. México, DF: Galilei/Universidad de Puebla, pp. 67-89.

Fideicomiso Educación Garantizada (2011). Resultados de la Encuesta a Beneficiarios del Programa Niñ@s Talento, ciclo escolar 2009-2010. Documento interno de trabajo de la Dirección de Evaluación del Fideicomiso Educación Garantizada. Gobierno del Distrito Federal.

(2011a). Resultados de la Encuesta a Padres de Beneficiarios del Programa Niñ@s Talento, ciclo escolar 2009-2010. Documento interno de trabajo de la Dirección de Evaluación del Fideicomiso Educación Garantizada.

(2014). Cuarto Informe Trimestral 2014. México, DF: Gobierno del Distrito Federal (2015). Tercer Informe Trimestral 2015. México, DF: Gobierno del Distrito Federal

Fukuyama, F. (1995). "Social Capital and the Global Economy". Foreign Affairs. 74(5), septiembre, pp. 89-103.

(2001). La gran ruptura. Punto de Lectura, Madrid.

Gaceta Oficial del Distrito Federal (2011). “Reglas de Operación del Programa Niñ@s

Talento". Publicadas por el Sistema para el Desarrollo Integral de la Familia del Distrito Federal (31 de enero de 2011), pp. 77-98.

Gagné, F. (1991). Toward a Differentiated Model of Giftedness and Talent. En Colangelo N. y Davis G. A. Handbook of Gifted Education. Edit. Allyn and Bacon, Boston, pp. 34-42.

(1993). "Constructs and Models Pertaining to Exceptional Human Abilities". Heller K., F. Mönks y A. Passow (Eds.). International Handbook of Research and Development of Giftedness and Talent. Oxford, Pergamon Press, pp. 99-130. (1997). “De la superdotación al talento: un modelo de desarrollo y su impacto en el lenguaje. Ideacción, 10, pp. 13-23.

Gardner, H. (1995). Arte, mente y cerebro: una aproximación cognitiva a la creatividad. Editorial Paidós, Buenos Aires, Argentina.

Galán, J. L. y I. Castro (2004). “Las relaciones inter-organizativas como fuente del capital social". Universia Business Review. Segundo trimestre: pp. 104-117.

Green, W. (2002). Econometric Analysis. New York: Cambridge University Press, pp. 88-123.

Heliwell, J. F. y R. O. Putnam (1995). “Economic Growth and Social Capital in Italy". Eastern Economic Journal, 21(3): 295-307.

Hirschman, A. O. (1982). Shifting Involvements: Private Interest and Public Action. Princeton, N. J.: Princeton University Press, pp. 110-140. (1986). El avance en colectividad: experimentos populares en América Latina. México, DF. Fondo de Cultura Económica.

Johnsen, Susan K. (2004). Identifying Gifted Students: A Practical Guide. Texas Association for the Gifted and Talented. Prufrock Press, Inc., pp. 22-64. 
Kliskberg, R. (2000). "Capital social y cultura, claves olvidadas del desarrollo". Instituto Interamericano para el Desarrollo Social, 7: 1-37.

Knack, S. y P. Keefer (1997). "Does Social Capital Have an Economic Payoff? A Cross-country Investigation". Quarterly Journal of Economics, 112(4): 1251-1288.

Leana, C. y H. J. Van Buren (1999). “Organizational Social Capital and Employment Practices". Academy of Management Review, 24(3): 538-555.

López Fernández, M.; F. Martín Alcázar, y P.M. Romero Fernández (2007). “Una revisión del concepto y evolución del capital social". Ayala-Calvo, J. C. y grupo FEDRA (coordinadores). Conocimiento, innovación y emprendedores: camino al futuro, 2007. Dialnet.

Marland, S. (1972). Education of the Gifted and Talent Report to the Congress of the United States by the U.S. Commisioner of Education. Government Publishing. Washington, D.C.

Mönks, F. (2003). Las necesidades de los híper-dotados: un modelo óptimo de respuesta. http:www.trainingvillage.gr/download/agora/themes/agora09/A9_Monks_ ES.pdf. (6 de mayo, 2008).

Mönks, F. y E. Mason (2000). “Developmental Psychology and Giftedness: Theories and Research". Heller K., F. Mönks, R. Sternberg y R. Subotnik (eds.). International Handbook of Research and Development of Giftedness and Talent. Oxford, Pergamon Press.

Narayan, D. y M. Cassidy (2001). "A Dimensional Approach to Measuring Social Capital: Development and Validation of a Social Capital Inventory". Current Sociology, 49 (2):59-102.

Passow, A. H. (1993). Planning for Talented Youth Teachers. Edit. College Press, New York.

(1993a). "National State Policies Regarding Education of the Gifted". Heller K.; F. Mönks y A. Passow (eds.). International Handbook of Research and Development of Giftedness and Talent. Pergamon Press, Oxford.

Portes, A. (1998). "Social Capital: Its Origins and Applications in Modern Sociology". Annual Review of Sociology. 24(1): 1-24.

Prieto, M. D. (2000). Los superdotados: esos alumnos excepcionales. Ediciones Aljibe. España, pp. 45-62.

Putnam, R.O. (1993). "The Prosperous Community: Social Capital and Public Life". The American Prospect, 13, pp. 112-140.

(1995). Bowling Alone: America's Declining Social Capital. Journal of Democracy, 6(1): 65-78.

Rayo, L. J. (1997). Necesidades educativas del superdotado. España: EOS.

Renzulli, J. S. (1986). “The Three-ring Conception of Giftedness: A Developmental Model of Creative Productivity". Sternberg R. J. y J. E. Davison, ed. Conceptions of Giftedness, Cambridge University Press, New York, pp. 210-145. 
Siles, M.; R. Lindon y S. D. Hanson (1994). “Does Friendly Service Retain Customers?" Bank Marketing. Enero, pp. 66-99.

Scott, J. (2004). "The Distribution of Benefits from Public Expenditure in Mexico. Public Expenditure Review. World Bank Report No. 27894, vol. II, pp. 88-112.

Sternberg, R. (1985). Beyond IQ a Triarchic Theory of Human Intelligence. Cambridge University Press, pp. 113-160.

Sternberg, R. y J. Davidson (1986). Conceptions of Giftedness. Cambridge University Press, pp. 75-89.

Stiglitz, J. (1998). "Formal and Informal Institutions". Dasgupta, P. y I. Serageldin, (eds.) Social Capital: A Multifaceted Perspective. Washington, D.C.: The World Bank, pp. 143-178.

Tannenbaum, A. J. (2000). "The Meaning and Making of Giftedness". N. Colangelo y A. Davis (eds.). Handbook of Gifted Education. Boston: Allyn and Bacon.

Terman, L. M. (1925). Mental and Physical Traits of a Thousand Gifted Children: Their Education and Development. Stanford University Press. Stanford, CA, pp. 99-155.

Tocqueville, A. (1835). La democracia en América, vol. 1. Alianza Editorial, Madrid.

UNESCO (2004). La educación de niños con talento en Iberoamérica. Santiago, Chile. Oficina Regional de Educación de la UNESCO para América Latina y el Caribe, pp. 18-43.

Woolcock, M. (1998). "Social Capital and Economic Development: Toward a Theoretical Synthesis and Policy Framework". Theory and Society, 27(2): 151-208.

Wooldridge, J. (2000). "Introductory Econometrics: A Modern Approach". SouthWestern Thomson Learning. (2002). Econometric Analysis of Cross Section and Panel Data. Cambridge, Masachusetts: The MIT Press, pp. 66-99.

Zavala B, Ma. Alicia (2004). “Desarrollo y validación de un sistema para la detección de alumnos con aptitudes sobresalientes-superdotados". Revista de Educación y Desarrollo, núm. 3, julio-septiembre, pp.13-20. Centro Universitario de Ciencias de la Salud. Universidad de Guadalajara. México.

\section{Referencias electrónicas}

http://www.dif.df.gob.mx .

Sistema para el Desarrollo Integral de la Familia del DF.

http://www.consejeria.df.gob.mx/gaceta/index.php.

Gaceta Oficial del Distrito Federal. "Lineamientos de Operación del Programa

Niñ@s Talento".

http://www.finanzas.df.gob.mx/.

"Programa General de Desarrollo del Distrito Federal 2007-2012". 